\title{
Navigation with laparoscopic ultrasound during fundus- first laparoscopic cholecystectomy-a single-centre retrospective case control study
}

Maciej Sebastian ( $\nabla$ mseba@op.pl )

Uniwersytet Medyczny im Piastów Śląskich we Wrocławiu https://orcid.org/0000-0002-1258-6358

\section{Agata Sebastian}

Uniwersytet Medyczny im Piastow Slaskich we Wroclawiu Biblioteka Glowna

\section{Jerzy Rudnicki}

Uniwersytet Medyczny im Piastow Slaskich we Wroclawiu

Research article

Keywords: cholecystolithiasis, laparoscopy, cholecystectomy, ultrasonography, bile ducts, anatomy

Posted Date: August 28th, 2020

DOI: https://doi.org/10.21203/rs.3.rs-60946/v1

License: (c) (7) This work is licensed under a Creative Commons Attribution 4.0 International License. Read Full License 


\section{Abstract \\ Background}

Laparoscopic cholecystectomy is considered as the gold standard treatment for cholecystolithiasis. The critical view of safety is a generally accepted technique of intraoperative visualization but during inflammation and fibrosis in the region of Calot's triangle it may fail. Fundus-first laparoscopic cholecystectomy with laparoscopic ultrasound navigation may be an attractive bail-out option when the intraoperative conditions are difficult.

\section{Methods}

The study group consisted of 900 patients with symptomatic cholecystolithiasis which was divided into two subgroups. The first subgroup where the only method of intraoperative identification was the critical view of safety consisted of 402 patients, the second subgroup where the critical view of safety and laparoscopic ultrasound were used consisted of 498 patients. In the first subgroup fundus-first laparoscopic cholecystectomy was performed in 13 patients, in the second subgroup in 42 patients. Statistical analysis included the MannWhitney $U$ test for continuous and Fisher's exact test for binary variables. The level of statistical significance was set at $95 \%(p<0.05)$.

\section{Results}

Fundus-first technique was significantly more often in the subgroup with laparoscopic ultrasound and the hospitalization time of fundus-first laparoscopic cholecystectomies was significantly shorter than in converted cases. The mean time of laparoscopic cholecystectomy and the mean time to obtain the transection level between the gallbladder and the hepatoduodenal ligament were significantly shorter and the conversion rate was significantly lower in the fundus-first and laparoscopic ultrasound group.

\section{Conclusions}

Fundus-first technique with laparoscopic ultrasound navigation may be a very efficient bail-out option during laparoscopic cholecystectomy due to a more precisely and significantly faster defined plane of dissection what enables safe performance of laparoscopic cholecystectomy with significantly lower rate of conversions.

\section{Background}

Fundus-first (FF) laparoscopic cholecystectomy (LC) is a technique which is used by some surgeons as a standard LC technique or, more often, as a bail-out procedure in case of a difficult LC [1-5]. Bile duct injury (BDI) or vasculobiliary injury (VBI) may be associated with the chronic inflammation in the region of Calot's triangle and difficulties to define the safe plane of dissection during FF technique [2]. There are several visual landmarks like the Rouvier's sulcus, the base of liver segment IV or the sentinel node which may help to avoid BDI or VBI, but during preparation and inflammation the anatomical conditions are usually changed [6]. Intraoperative cholangiography (IOC) is an invasive procedure and cannulation of the cystic duct is not always possible due to 
fibrous obliteration of tissues [4]. The only method which in such situation may safely visualize both vascular and avascular structures and define the proper plane of dissection is laparoscopic ultrasound (LUS) [7]. LUS seems to be extremely useful during FF LC because the level of safe tissue transection may be very precisely defined. Another goal of FF technique is the reduction of the conversion rate [5, 8]. During FF dissection without LUS in case of inflammation and fibrosis in the region of the gallbladder's neck the conversion should not be delayed if at any point the anatomy is not clear $[5,9]$. With LUS the anatomy behind the visible plane of dissection is clearly defined and the only factor which may disable safe FF LC are tissues laparoscopically undissectable.

\section{Methods}

The study group consisted of 900 patients operated on between January 2010 and February 2020 in one Department of Surgery. Inclusion criterion for the study was the symptomatic cholecystolithiasis. Exclusion criterion was the pre- or postoperatively diagnosed cancer of the gallbladder, preoperative acute cholecystitis and previous operations in the abdominal cavity. The study group was divided into two subgroups. The first subgroup where the only method of intraoperative navigation was the critical view of safety (CVS) consisted of 402 patients (220 women and 182 men), the second subgroup where CVS and LUS were used consisted of 498 patients ( 277 women and $221 \mathrm{men}$ ). In the first subgroup FF LC was performed in 13 patients (FF group), in the second subgroup in 42 patients (FF + LUS group). Written informed consent was obtained from all patients before surgery. All procedures were in accordance with the ethical standards of the 1964 Declaration of Helsinki and its later amendments and the study was approved by the Ethical Committee of the Wroclaw Medical University (approval number BW-24/2020).

Cholecystectomies were performed on an elective basis by three surgeons experienced in LC/open cholecystectomy (> 150 cholecystectomies) and LUS ( $>70$ examinations). For LUS were used the laparoscopic probe Toshiba PEF-704 LA (frequency 7.0-10 MHz) and the diagnostic ultrasound system Toshiba NemioMX SSA-590A all manufactured in Japan. LUS was performed in every patient from the second subgroup.

Laparoscopic ultrasound probe was inserted through the epigastrical $10 \mathrm{~mm}$ (transverse view) or the umbilical $10 \mathrm{~mm}$ trocar (longitudinal view). Vascular and avascular structures were differentiated with power doppler function. The dissection started initially in the region of Calot's triangle and there was an attempt to reach the critical view of safety (CVS) but when the inflammatory plane was hard to prepare the FF technique was used (Fig. 1) (Video 1). When the anatomy was unclear or the fibrous tissues were undissectable there was an attempt to perform subtotal cholecystectomy or the operation was converted. When there were problems with the traction during FF LC the liver was kept elevated by retractor. The key structure which was visualized throughout the procedure and defined the proper plane of dissection during LUS was the "Mickey Mouse sign"-a characteristic configuration of the bile duct, the proper hepatic artery and the portal vein in the hepatoduodenal ligament which is similar to the head of Mickey Mouse (Fig. 2).

Statistical analysis included the Mann-Whitney $U$ test for continuous and Fisher's exact test for binary variables. The level of statistical significance was set at $95 \%(p<0.05)$.

\section{Results}


The FF technique was significantly more often $(p=0.002)$ in the subgroup with LUS and the hospitalization time of FF LCs was significantly shorter than in converted cases. The mean time of LC and the mean time to obtain the transection level between the gallbladder and the hepatoduodenal ligament were significantly shorter and the conversion rate was significantly lower in the FF + LUS group (Tables 1 and 2). There were no significant differences between the two groups according to the age, the rate of bile duct injury and subtotal cholecystectomy (Tables 1 and 2). Two BDIs in the FF group were the leakages from the cystic stump (Strasberg A) after subtotal fenestrating cholecystectomy which were treated successfully with the endoscopic retrograde cholangiopancreatography. The reason for conversion in the FF + LUS group was the laparoscopically undissectable fibrous tissue which disabled safe performance of the procedure (3 patients) whereas in the FF group these were unclear anatomy (2 patients), undissectable fibrous tissue (2 patients) and bleeding (1 patient).

Table 1: Characteristics of the study group according to the age, operating time of laparoscopic cholecystectomy, time needed to obtain transection level between the gallbladder and the hepatoduodenal ligament and the length of hospital stay.

\begin{tabular}{|c|c|c|c|c|c|c|c|c|c|c|c|c|}
\hline \multirow[t]{4}{*}{ parameter } & \multicolumn{3}{|c|}{ Age [years] } & \multicolumn{3}{|c|}{$\begin{array}{l}\text { Operating time of } \\
\text { laparoscopic } \\
\text { cholecystectomy } \\
\text { [min] }\end{array}$} & \multicolumn{3}{|c|}{$\begin{array}{l}\text { Time needed to } \\
\text { obtain transection } \\
\text { level [min] }\end{array}$} & \multicolumn{3}{|c|}{$\begin{array}{l}\text { Length of hospital stay } \\
\text { [days] }\end{array}$} \\
\hline & \multirow[t]{3}{*}{ Total } & \multirow[t]{3}{*}{$\mathrm{FF}$} & \multirow{3}{*}{$\begin{array}{l}\text { FF } \\
+ \\
\text { LUS }\end{array}$} & \multirow[t]{3}{*}{ Total } & \multirow[t]{3}{*}{ FF } & FF & \multirow[t]{3}{*}{ Total } & \multirow[t]{3}{*}{ FF } & FF & \multirow[t]{3}{*}{ Total } & \multirow{3}{*}{$\begin{array}{l}\text { FF, } \\
\text { FF } \\
+ \\
\text { LUS }\end{array}$} & \multirow[t]{3}{*}{ Conversion } \\
\hline & & & & & & + & & & + & & & \\
\hline & & & & & & LUS & & & LUS & & & \\
\hline mean & 61 & 62 & 60 & 57 & 64 & 55 & 36 & 44 & 35 & 6 & 4 & 7 \\
\hline $\begin{array}{l}\text { standard } \\
\text { deviation }\end{array}$ & 10 & 9 & 11 & 12 & 13 & 11 & 8 & 7 & 7 & 2.6 & 0.6 & 3 \\
\hline minimum & 43 & 45 & 43 & 41 & 45 & 41 & 24 & 34 & 24 & 4 & 4 & 5 \\
\hline maximum & 81 & 78 & 81 & 84 & 84 & 82 & 54 & 54 & 46 & 19 & 6 & 19 \\
\hline median & 62 & 64 & 58 & 55 & 60 & 54 & 35 & 45 & 33 & 5 & 5 & 6 \\
\hline significance & - & $p=$ & & - & $p=$ & $232^{*}$ & - & $p=$ & $004^{*}$ & - & $P<C$ & $001^{*}$ \\
\hline
\end{tabular}

*Statistically significant values $(p<0.05)$

LUS-laparoscopic ultrasound

FF-fundus-first cholecystectomy 
Table 2: Characteristics of the study group according to the number of conversions, biliary injury in the form of a leakage from the cystic duct and subtotal laparoscopic cholecystectomy.

\begin{tabular}{|c|c|c|c|c|c|c|c|c|c|}
\hline \multirow[t]{2}{*}{ parameter } & \multicolumn{3}{|c|}{ Conversions } & \multicolumn{3}{|c|}{$\begin{array}{l}\text { Biliary Injury in the form of a leakage } \\
\text { from the cystic duct }\end{array}$} & \multicolumn{3}{|c|}{$\begin{array}{l}\text { Subtotal laparoscopic } \\
\text { cholecystectomy }\end{array}$} \\
\hline & Total & $\mathrm{FF}$ & $\mathrm{FF}$ & Total & FF & $\mathrm{FF}$ & Total & FF & $\mathrm{FF}$ \\
\hline & & & + & & & + & & & + \\
\hline & & & LUS & & & LUS & & & LUS \\
\hline $\begin{array}{l}\text { Number of } \\
\text { patients }\end{array}$ & 8 & 5 & 3 & 2 & 2 & 0 & 9 & 3 & 6 \\
\hline Significance & - & \multicolumn{2}{|c|}{$p=0.04^{*}$} & - & \multicolumn{2}{|c|}{$p=0.066$} & - & \multicolumn{2}{|c|}{$p=0.7$} \\
\hline
\end{tabular}

*Statistically significant values $(p<0.05)$

LUS-laparoscopic ultrasound

FF-fundus-first cholecystectomy

\section{Discussion}

The rate of $\mathrm{BDI}$ during $\mathrm{LC}$ has reached the level of $0.08-0.2 \%$ and is comparable with the open cholecystectomy era what may be associated with better surgical skills, improved instrumentation and the number of LCs performed over "learning curve" [10-12]. The Research Institute Against Cancer of the Digestive System (IRCAD) defines three major causes of BDI: (1) technique associated with the surgeon's experience and performance, (2) pathology related to the extent of inflammation and (3) presence of anatomical variations whereas the most common reason of $\mathrm{BDI}$ is the misidentification of the common hepatic/bile duct instead of the cystic duct [10, $13,14]$. The safest way to complete cholecystectomy is to obtain CVS but the problems may arise in the case of inflammation in the region of Calot's triangle $[10,13,14]$. CVS is not a dissection technique, but rather a technique of identification similar to the safety measures during hunting or flying $[13,15]$. There is no need to expose the common bile or hepatic duct while obtaining CVS [2]. CVS usually protects against incorrect identification but not against BDI and VBI during dissection when the local conditions are changed [15]. The possible bail-out techniques when CVS can not be reached include FF LC, subtotal LC, tube cholecystostomy or conversion $[2,16]$.

FF LC is an alternative technique when there is a severe inflammation or fibrosis in the triangle of Calot [10]. During FF LC the gallbladder is dissected off the liver bed beginning with the fundus towards the infundibulum until it is hanging on the cystic duct and the cystic artery or it may be combined with the subtotal cholecystectomy [2]. The preferred dissection technique should be between the subserosal outer and inner layer of the gallbladder wall but in case of inflammation it may be very difficult [6]. The complications may involve haemorrhage from the liver bed or the gallbladder wall, migration of stones into the common bile duct or BDI/VBI associated with improper plane of dissection and higher rate of perforation of the gallbladder wall thus a stepby-step preparation and proper hemostasis are advised $[2,3,5]$. During standard technique the grasper on the fundus of the gallbladder is used to apply traction to expose the triangle of Calot [4]. When there are problems 
with the traction during FF the liver may be kept elevated by retractor [4]. LUS defines very precisely the border between the gallbladder neck and common bile/hepatic duct enabling safe dissection plane. LUS is noninvasive, there is no need to cannulate the cystic duct and use the contrast dye. It is safe for both the patient and operating team and may be repeated as many times as it is needed [7]. IOC in case of advanced inflammatory changes usually fails $[4,5]$.

FF technique leads to the reduction of conversion rate. The reported conversion rate for elective LC is $4-6 \%$ and for acute LC is $5-10 \%$ but recently the reported conversion rate was also very low at $0.04 \%[2,17]$. Mangieri et al. had an incidence of BDI in converted cases at the level of $15 \%$ what makes the conversion with the current era of surgeons not experienced with the open approach a doubtful safe bail-out option because the worst VBI often occur after conversion $[8,17,18]$. According to our study FF technique with LUS enables safe performance of LC with significantly lower conversion rate associated with improved postoperative recovery.

Another bail-out option is subtotal cholecystectomy which may be performed in two ways. The first option entails removal of peritonealised part of the gallbladder leaving the remnant of the wall in liver bed and closure of the cystic duct orifice from the inside with a purse string suture. The gallbladder remnant is either left open in fenestrating variant or oversewn in the second reconstituting variant [2]. The latter may expose the patient to the recurrence of gallstone disease due to the closed remnant of the gallbladder (with the rate of 2.2\%) but the open variant is associated with higher bile leaks (10.6\%) $[10,13,14,19]$. The key to successful subtotal cholecystectomy is to remove as much as possible gallbladder wall but the surgeon is sometimes not sure where to stop and at which level close the remnant of the gallbladder. The same as with the FF technique LUS defines very precisely the safe plane of dissection without the risk of BDI and VBI. It enables to close the remnant of the gallbladder as close as possible to the bile duct without the risk of the bile leak as in fenestrating variant without a functional gallbladder remnant as in reconstituting variant.

Handzel et al. proposed a semi-top-down technique of LC where dissection starts well above the infundibulum and is directed laterally with the fundus of the gallbladder staying in place for traction. In this method it is important to identify anatomic landmarks before dissection starts-Rouviere's sulcus, the common bile duct and the gallbladder infundibulum [18]. As we mentioned before these are visual landmarks which in case of inflammation may be difficult to attain making this method in such situation unreliable. Another authors stated that FF LC should be taught to surgical residents when faced with the difficult LC and the FF technique should be in the armamentarium of the laparoscopic surgeon $[4,20]$.

The limitation of our research was a relatively small number of FF LCs and a single- center type of the study, thus further studies including larger groups of participants in more than one surgical center are needed in order to strengthen our findings and confirm the usefulness of LUS during FF LC, especially in protection against BDI and VBI.

\section{Conclusions}

To conclude, FF technique under the control of LUS may be an attractive bail-out option in comparison to the standard technique of FF due to a very precisely and significantly faster defined plane of dissection which enables safe performance of LC with significantly lower rate of conversions. 


\section{Abbreviations}

BDI-bile duct injury

CVS-critical view of safety

FF-fundus-first

IOC-intraoperative cholangiography

IRCAD-Research Institute Against Cancer of the Digestive System

LC-laparoscopic cholecystectomy

LUS-laparoscopic ultrasound

VBI-vasculobiliary injury

\section{Declarations}

\section{Ethics approval and consent to participate}

Written informed consent was obtained from all patients before surgery and the study was approved by the Ethical Committee of the Wroclaw Medical University (approval number BW-24/2020).

\section{Consent for publication}

Written informed consent for publication was obtained from patients.

\section{Availability of data and materials}

The datasets used and analyzed during the current study are available from the corresponding author on reasonable request.

\section{Competing interests}

The authors declare that they have no competing interests.

\section{Funding}

The authors report no grant or financial support

\section{Authors contributions}

Project development: MS, AS, JR. Data acquisition and interpretation: MS, AS. Statistical analysis: MS, AS. Manuscript drafting: MS, AS, JR. Manuscript revision and accountable for all aspects of the work: MS, AS, JR. All the authors approved the final version of the manuscript. 


\section{Acknowledgements}

None.

\section{References}

1. Cengiz Y, Lund M, Jänes $A$, et al. Fundus first as the standard technique for laparoscopic cholecystectomy. Sci Rep. 2019;9(1):18736.

2. Manatakis DK, Papageorgiou D, Antonopoulou MI, et al. Ten-year Audit of Safe Bail-Out Alternatives to the Critical View of Safety in Laparoscopic Cholecystectomy. World J Surg. 2019;43(11):2728-33.

3. Rosenberg J, Leinskold T. Dome down laparosonic cholecystectomy. Scand J Surg. 2004;93(1):48-51.

4. Kelly MD. Laparoscopic retrograde (fundus first) cholecystectomy. BMC Surg. 2009;9:19.

5. Mahmud S, Masaud M, Canna K, et al. Fundus-first laparoscopic cholecystectomy. Surg Endosc. 2002;16(4):581-4.

6. Honda G, Hasegawa H, Umezawa A. Universal safe procedure of laparoscopic cholecystectomy standardized by exposing the inner layer of the subserosal layer (with video). J Hepatobiliary Pancreat Sci. 2016;23(9):E14-9.

7. Dili A, Bertrand C. Laparoscopic ultrasonography as an alternative to intraoperative cholangiography during laparoscopic cholecystectomy. World J Gastroenterol. 2017;23(29):5438-50.

8. Sormaz IC, Soytaş Y, Gök AFK, et al. Fundus first technique and partial cholecystectomy for difficult laparoscopic cholecystectomies. Ulus Travma Acil Cerrahi Derg. 2018;24(1):66-70.

9. Porter DJ, Walter A, Lucocq J, et al. Sub-Total Cholecystectomy - An Audit of Clinical Practice in a Tertiary Referral Hospital. World J Surg Surgical Res. 2020;3:1190.

10. Conrad C, Wakabayashi G, Asbun HJ, et al. IRCAD recommendation on safe laparoscopic cholecystectomy. J Hepatobiliary Pancreat Sci. 2017;24(11):603-15.

11. Halbert C, Altieri MS, Yang J, et al. Long term outcomes of patients with common bile duct injury following laparoscopic cholecystectomy. Surg Endosc. 2016;30(10):4294-9.

12. Halbert C, Pagkratis S, Yang J, et al. Beyond the learning curve: incidence of bile duct injuries following laparoscopic cholecystectomy normalize to open in the modern era. Surg Endosc. 2016;30(6):2239-43.

13. Strasberg SM. A perspective on the critical view of safety in laparoscopic cholecystectomy. Ann Laparosc Endosc Surg. 2017;2:91.

14. Singh R, Brunt LM. Critical view of safety-its feasibility and efficacy in preventing bile duct injuries. Ann Laparosc Endosc Surg. 2018;3:2.

15. Strasberg SM, Brunt LM. Rationale and use of the critical view of safety in laparoscopic cholecystectomy. $J$ Am Coll Surg. 2010;211(1):132-8.

16. Hussain A. Difficult laparoscopic cholecystectomy: current evidence and strategies of management. Surg Laparosc Endosc Percutan Tech. 2011;21(4):211-7.

17. Mangieri CW, Hendren BP, Strode MA, et al. Bile duct injuries (BDI) in the advanced laparoscopic cholecystectomy era. Surg Endosc. 2019;33(3):724-30. 
18. Handzel RM, Peitzman AB. Laparoscopic cholecystectomy: semi-top-down technique. Ann Laparosc Endosc Surg. 2019;4:60.

19. Iwashita Y, Hibi T, Ohyama T, et al. Delphi consensus on bile duct injuries during laparoscopic cholecystectomy: an evolutionary cul-de-sac or the birth pangs of a new technical framework? J Hepatobiliary Pancreat Sci. 2017;24(11):591-602.

20. Alley JR Jr, Stucky CC, Moncure M. Teaching surgical residents dome-down laparoscopic cholecystectomy in an academic medical center. JSLS. 2008;12(4):368-71.

\section{Figures}
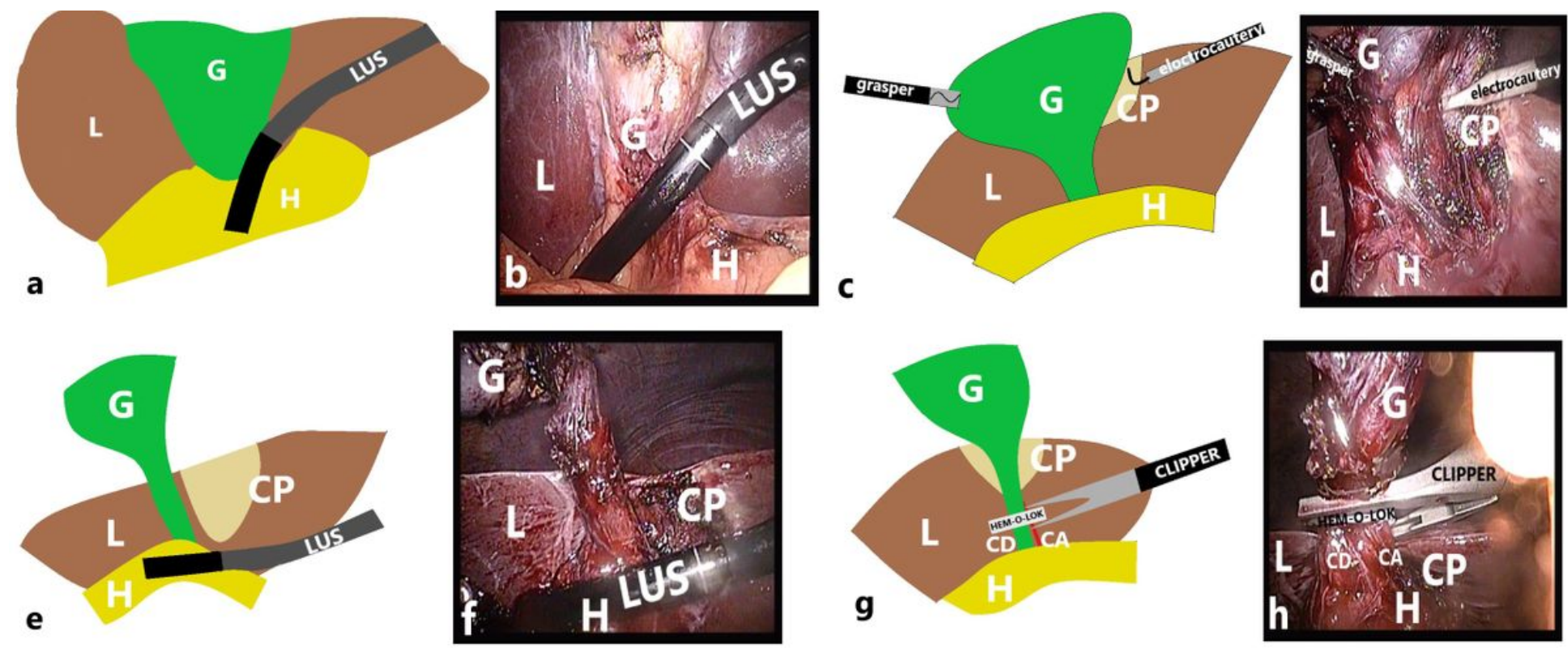

\section{Figure 1}

The next steps of the fundus-first laparoscopic cholecystectomy with the laparoscopic ultrasound navigation; a, b-LUS defines the safe plane of dissection before the preparation starts, c, d-in case of inflammation and fibrosis in the region of Calot's triangle the fundus-first dissection is performed, e, f-when the fundus-first dissection is finished the proper level of transection between the gallbladder and the hepatoduodenal ligament is established with LUS, g, h-in case of advanced fibrosis the cystic duct and the cystic artery are clipped with one XL Hem-o-lok clip on the earlier defined level without narrowing and injury to the elements of the hepatoduodenal ligament. CAcystic artery CD-cystic duct CP-cystic plate G-gallbladder H-hepatoduodenal ligament L-liver LUS-laparoscopic ultrasound 

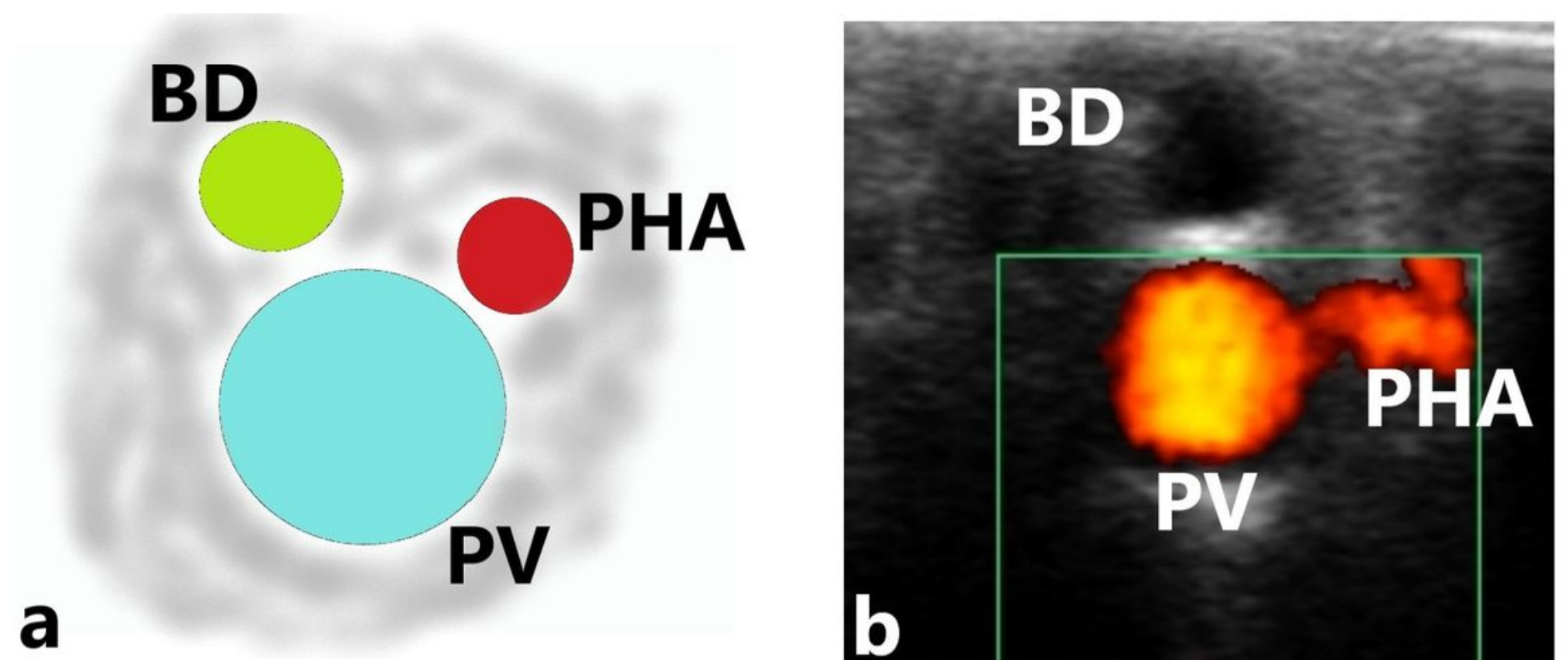

\section{Figure 2}

a, b-“Mickey Mouse sign" established with laparoscopic ultrasound with power doppler function. BD-bile duct PHA-proper hepatic artery PV-portal vein Table legends

\section{Supplementary Files}

This is a list of supplementary files associated with this preprint. Click to download.

- Video1.AVI 